\title{
AMERICAN RHEUMATISM ASSOCIATION
}

\author{
PROCEEDINGS OF THE ANNUAL MEETING, 1947
}

The Annual Meeting of the American Rheumatism Association was held in Atlantic City, New Jersey, on June 7, 1947. The Presidential Address was delivered by Dr. Walter Bauer, and this address, together with reports of all papers read at the meeting and discussions on them, is printed below.

\section{PRESIDENTIAL ADDRESS}

\section{The Challenge of Adolescence WALTER BAUER}

The American Rheumatism Association is a young medical society. This year, 1947, marks its fifteenth birthday. Endocrinologically speaking, the society has reached the age of puberty. Its activities during the first fifteen years of life have been in accord with the purposes for which the society was conceived. Its record of accomplishment, despite the interruption of the war years, affords grounds for encouragement and legitimate hope of a successful adolescence. If the latter is achieved, we shall witness a maturity evidenced by marked scientific and clinical advancement in the fields of rheumatic and allied diseases. It is the adolescent phase of the society's development with which I wish to concern myself during this brief address.

The growth requirements during this period of adolescence are many. The most important of these are: a diversified and distinguished membership and adequate support of their research activities. The former is the responsibility of the Membership Committee; the latter, the obligation of the Committee on Research and Education. If the latter group recommends that our society embark on a national fund-raising campaign in order to provide needed financial support, it will be the duty of our membership to foster a vigorous educational, research, and care-of-the-patient programme.

I will not dwell on the first of these requisiteseducation-other than to remind you of the Hippocratic oath which reads, "I will impart this art by precept, by lecture, and by every mode of teaching."

The need for both clinical and basic research in the field of rheumatic diseases is ever evident. Time will not permit an adequate presentation of this second requisite. It will suffice to state that the search for specific remedies has led nowhere. Some will accuse me of medical nihilism if I express my views on this subject by modifying slightly the classic observation by Oliver Wendell Holmes: "If most of the so-called specific rheumatic medicines were thrown into the Atlantic ocean, it would be much better for mankind and so much worse for the fishes."

Through accurate clinical studies, we can advance our knowledge of the natural history of the rheumatic and allied diseases and also determine the type of bodily changes which ensue.

The urgency for basic research is, I am sure, obvious to all students of rheumatic diseases. This will necessitate a better definition of pathogenesis, and the mechanisms involved will remain unchanged. Such definition of tissue, both normal and diseased, will require the employment of the newer techniques introduced by the histochemist, the physical chemist, and those interested in molecular structure. To cite but one example, until such an approach is undertaken we will not know why tissues high in mucin content are predominantly involved in rheumatoid arthritis.

Adequate care of the patient will always be an absolute requisite of the members of this society. This being the case, we must make use of every known preventive and curative measure for communities as well as for individuals. The need for the former is especially great. Such community programmes of care should be the responsibility of the affiliated groups and should also include convalescence and rehabilitation.

It is also essential that the student of rheumatic diseases understand the reaction to illness. " $\mathrm{He}$ must be familiar not only with the personality involved, but also with certain psychological concepts related to disability. Thus, attention must be directed not only to the degree of structural impairment, but also to the personality as it relates to past capacities and flexibilities, as well as to its means of adapting to the specific disability. The emotional setting of the illness, the special meaning of the disability to the individual, and the past and present means used by the individual to manage or handle anxiety mobilized by disability, require particular attention. Of equal importance is the character of the medical attention. Many individuals are harmed 
through the use of repetitive and unnecessary diagnostic procedures which in many instances reinforce certain basic emotional patterns. Last, but not least, the emotional capacity of the physician to deal with disabled people without adopting hostile attitudes is of primary importance in any therapeutic programme."

I sincerely hope that this society will not sponsor an American board for physicians interested in rheumatic diseases. The folly of such, I am sure, is apparent to some of you. I also hope that if special clinics or units for the study of rheumatic diseases are established, they will become, wherever possible, an integral part of large, general hospitals and not isolated institutions. In my opinion, the latter are very likely to suffer from the lack of stimulus obtained from the other departments of a general hospital.

I fully appreciate that the foregoing account of the requisites for a successful adolescence and maturity of our society have been presented all too briefly. However, the detailed requirements can be supplied as we move upward on the growth curve. As we proceed forward, we must be ever mindful that the contributions of a society reflect the attitudes and activities of its membership.

\section{SYMPOSIUM ON COLLAGEN}

\section{Electron Microscope Study of the Structure of Connective Tissue}

\section{JEROME GROSS}

The fine structure of collagen has been the subject of intensive research in the Department of Biology at the Massachusetts Institute of Technology for the past five years. Electron microscopy and $x$-ray diffraction studies have contributed considerable information concerning the submicroscopic architecture of this fibrous protein. Schmitt and others ${ }^{1}$ demonstrated with the electron microscope the presence of an axial periodicity of 640 Angstrom units between electron dense and light bonds in the collagen fibrils. This figure coincided exactly with the spacing previously determined by Bear ${ }^{2}$ of this laboratory using $x$-ray diffraction. Staining the collagen fibril with phosphotungstic acid revealed at least five sub-periods within the larger period. Shadow casting has demonstrated the presence of contour discontinuities of the same periodicity. This general pattern has been observed in collagen of fish, amphibia, and various mammals including

1 J. cell. comp. Physiol., 1942, 20, 11.

2 J. Amer. chem. Soc., 1942, 64, 727.

D man. It is also present in the collagen of all tissues examined thus far.

Schmitt and others showed the presence of longitudinal cleavage planes in the collagen fibril and demonstrated the same axial periodicity in the component sub-fibrils. Swelling in dilute acid will cleave the fibrils to filaments of the order of 100 Angstrom units in width, which are readily visualized when shadowed. The fine structure of these filaments and the nature of the cross-striations in the larger fibrils are being studied intensively.

Because of the close association of the acid polysaccharides, hyaluronic acid, and chondroitin sulphate with connective tissue, their occurrence in other structures, such as cartilage, vitreous humour, cornea, umbilical cord, synovial fluid, and some tumours, an investigation of these substances is now under way. Electron micrographs of hyaluronate reveal fibrous patterns which reflect the degree and possibly the form of polymerization.

It is believed that the elucidation of the structure of collagen and associated substances may promise a basis for understanding some of the pathological changes which occur in connective tissue.

\section{Cement Substances of Connective Tissue} KARL MEYER

Histologically two types of interfibrillar material have been distinguished: first, the amorphous and viscous ground substance; and secondly, the metachromatically-staining cement substances proper which are supposed to form a fine sheath around the individual fibrils. Both types of interfibrillar substances consist mainly of proteins and mucopolysaccharides. While the nature of the proteins is unknown, the mucopolysaccharides have been characterized, at least in some connective tissues, as hyaluronic acid and as a chondroitin sulphate. Hyaluronic acid, a polymer of acetylglucosamine and glucuronic acid, has a molecular weight of 200 to 500,000 and more, and has been isolated from mesodermal tissues, vitreous, and synovial fluid, and group A streptococci. The enzyme depolymerizing and hydrolyzing hyaluronic acid has been named hyaluronidase; it is the cause of the "spreading reaction" in the skin.

Chondroitin sulphates, polymers of acetylgalactosamine-sulphate and glucuronic acid, have likewise molecular weights of several hundred thousand. In contrast to hyaluronic acid they may have branched chains. The protein complexes of chondroitin sulphates are more stable than those of hyaluronate, forming in some tissues at least stable compounds, while hyaluronic acid forms only polar complexes with proteins which are easily dissociated. 
Synovial fluid seems to be formed partly by dialysis and partly by secretion. The viscosity of the fluid is practically due only to hyaluronic acid. By a turbidimetric method normal and pathological fluids were compared, and the normal showed greater viscosities but lower hyaluronic acid concentrations. Furthermore, hyaluronic acid of pathological fluids precipitates with acidified protein, forming a stable turbidity, while that of normal fluids precipitates as fibres. The fibre formation is prevented by previous incubation with $1 / 100$ of a unit of hyaluronidase. Whether the difference in degree of polymerization between normal and pathological fluids is due to hyaluronidase activity is not known at present.

The chemistry of connective tissue may be correlated with the histology if we assume that the amorphous ground substance contains hyaluronic acid while the cement substances contain different chondroitin sulphates as their typical components.

\section{Lesions Resulting from Albumin and Globulin Injections}

\section{C. v. Z. HAWN}

1. Groups of normal rabbits were given single intravenous injections of foreign proteins in doses of $1 \mathrm{~g}$. per kilo, bled at regular intervals for serologic studies, and sacrificed after varying lengths of time for pathological studies. The protein solutions used were of crystallized bovine serum albumin, bovine serum gamma globulin, and bovine serum. The experiments were planned, first, to correlate the sequence of pathological and immunological changes, and second, to compare the responses to two chemically and immunologically distinct plasma protein fractions and to the whole serum of the same species.

2. (a) The principal pathological lesions in rabbits given bovine serum were similar to those which have been previously observed following the injection of horse serum and were characterized by widely dispersed but segmental acute inflammatory lesions of the arteries. These lesions were at their height two weeks after injection and showed marked repair at four weeks. (b) Crystallized bovine serum albumin produced lesions almost exclusively confined to the arteries, which were at their height at two weeks, were healing at three, and healed by four weeks. The lesions were less numerous and less intense than in animals given whole serum and were only found in some of the animals. (c) Bovine serum gamma globulin elicited quite different histologic sequences. The most striking lesions involved the glomeruli of the kidneys, and to a lesser degree, the heart. Lesions in the liver and joints were present but less conspicuous, and arterial lesions were rare and slight in degree. The lesions not only differed from those in rabbits given albumin in distribution but in timing, since they were most widespread and acute at one week and were healing at two weeks after injection. Moreover, lesions were observed in almost every animal.

3. Results of immunological studies were consistent with the interpretation that the pathological lesions were due to an antigen-antibody reaction in the tissues, as shown by the following: (a) acute lesions were observed only when antigen was present and before antibody appeared in the circulation. (b) healing of lesions was observed (with one exception) only when antigen had almost or completely disappeared from the circulation, usually with the appearance of antibody; (c) there was a correlation between the rapidity of evolution of the lesions and the rapidity with which the antigen disappeared from the circulation; $(d)$ there was a rough correlation between the proportion of animals showing lesions and the proportion developing antibodies after the injection of a particular protein solution.

(Illustrations to this paper were shown.)

\section{The "Pararheumatic Diseases" PAUL KLEMPERER}

It is generally accepted that the morbid anatomy of rheumatic fever is characterized by a more or less systemic involvement of the connective tissues. This involvement becomes first evident as fibrinoid alteration of the collagen fibres and swelling of the homogeneous ground substance. It is followed by cellular proliferation which, especially in the heart, assumes the characteristic form of Aschoff nodules. Because of the absence of demonstrable pathogenic organisms, Klinge assumed that the tissue damage in rheumatic fever was determined by hypersensitivity of the host. The occurrence of similar connectivetissue changes in experimental local anaphylaxis seems to lend support to this hypothesis. The observations of striking fibrinoid alterations of the vasculature suggested to Klinge a similar pathogenesis for periarteritis nodosa, malignant sclerosis, and thromboangiitis obliterans. Because of the presence of widespread identical connectivetissue lesions in acute lupus erythematosus and scleroderma these diseases were also included within the group of maladies with an allergic background. Roessle proposed that " the old designation, rheumatic, should yield to the new wider concept of allergic diseases ". Theilum, accepting the haemolytic streptococcus as the cause of rheumatic fever, suggested the term "pararheumatic" to indicate the possible difference in specific aetiology of the 
various other members of the group of diseases with a common pathogenetic background of allergy.

In our studies of acute lupus erythematosus and generalized scleroderma, Baehr, Schifrin, Pollack, and I were also impressed by the frequent widespread implication of the connective tissue. "We were fully aware of the possible significance of allergy in the causation of fibrinoid collagen alteration; but we were hesitant to accept this aetiology because of these histological features only, especially since classical manifestations' of allergy are absent in the clinical course of these diseases. Moreover, we were cognizant of the fact that collagen alterations identical with or hardly distinguishable from those seen in allergy can be produced experimentally by various factors. More fundamental information regarding the nature and cause of the fibrinoid alteration of the collagen fibres is necessary before we can approach the problem of the aetiology of human disease characterized by diffuse collagen changes.

\section{Discussion on Symposium on Collagen}

Dr. Charles Ragan (New York): We have been interested in the hyaluronic-acid content of joint fluid for about five years, and the implications of what we have found still need explanation; however, we have observed, on tapping knee joints post mortem, that normal human fluid is very viscous, much more viscous than any pathological fluids. We have obtained fluid from patients with rheumatoid arthritis, osteo-arthritis, and rheumatic fever. A small amount of fluid is obtained from a normal joint, and the viscosity is difficult to measure in such small amounts of fluids. We have had to approximate it by dilution curves, but we feel that the results are accurate enough to say that the viscosity of normal fluids is very high. However, the hyaluronic acid content is not much greater, which would mean that in normal fluids the hyaluronate is in a more or less polymerized state. We have evidence that in the abnormal states the hyaluronic acid has been depolymerized to some extent. This has been obtained by plotting the viscosity on the ordinate and the concentration of hyaluronic acid on the abscissa. On such a curve, similar to the dilution curve, normal fluids appear to the left, which would indicate that the abnormal fluids have been exposed to some hyaluronidase. These fluids, when standing at icebox temperature, if kept sterile, do not change in viscosity, which would indicate that no hyaluronidase is present.

Speaking as a clinician, I think we are almost convinced that rheumatoid arthritis is a disease of hypersensitivity, but we still do not know what the antigen is, or how to approach the disease from this angle.

Dr. Marian W. Ropes (Boston, Massachusetts): We also have been very much interested in the hyaluronic acid content of joint fluids for about fifteen years and have found similarly that the normal viscosity is very high, while the relative concentration of the hyaluronic acidprotein compound is not very high. In fluids from joint diseases there is considerable variation. In the rheuma- toid fluids we find a comparatively. low concentration of hyaluronate per unit volume with low viscosity, much lower than normal fluid. In rheumatic fever we find relatively little change from normal in the viscosity per unit concentration, and in disseminated lupus we find viscosities in the range of normal fluids, and sometimes an actually higher than normal concentration of mucin per unit volume. We have attempted to correlate the breakdown of hyaluronic acid in rheumatoid fluids by comparing the log of the viscosity with the square root of the concentration of the glucosamine of the hyaluronic acid. This gives a straight-line relationship in normal fluid. We have attempted to use this relationship as evidence of the degree of breakdown of hyaluronate, but it has not been consistent in all fluids. We still feel it is impossible to say whether or not the change in hyaluronic acid in rheumatoid arthritis is due to a breakdown or to inadequate synthesis due to the lack, possibly, of the proper enzyme. We have been unable to find hyaluronidase activity in sterile normal joint fluid or in fluid from any joint disease that we have tested. Also, we have tried to demonstrate it in normal and abnormal synovial membranes, but if the preparations remain sterile we have found no hyaluronidase activity.

Has Dr. Klemperer been able to obtain metachromatic staining with toluidine blue from isolated compounds that do not contain sulphate? In our experience to date we have not been able to do so.

Dr. Richard H. FreYberg (New York): I should like to ask Dr. Gross whether studies have been done or are being contemplated with electron microscopy of abnormal connective-tissue fibres.

Dr. Meyer's presentation was of great interest to me. Many of us have felt that the histologic changes and many clinical problems of rheumatoid arthritis are probably due to antigenic or enzymatic changes. The studies Dr. Meyer has done certainly open the door for us to make reasonable explanation for some abnormalities of connective tissue on the basis of either immunologic or enzymatic alterations.

The acute lesions that Dr. Hawn showed in his excellent illustrations, that result from a single injection of albumin, indicate how extensive is the effect and damage from such a single insult. Repeated insults and the continuity of resulting abnormalities going on in a chronic disease such as rheumatoid arthritis, would reasonably explain the mixture of changes of developing and advancing disease, together with healing and scarring which constitute the pathological picture that we see and which we should like to know more about from the functional standpoint.

Does Dr. Hawn have explanation for the different speeds of decrease of the albumin and globulin from the blood stream? Is this phenomenon related to differences in molecular weight? Has he studied the effect of proteins other than normal albumin, globulin, or serum injected into animals? Do similar pathologic changes result from the injection of digestion products of serum, or albumin, or from different proteinates?

We should all give serious thought to the papers of this symposium, to stimulate related studies which are so badly needed. 
Dr. William D. Robinson (Ann Arbor, Michigan): $I$ wish to ask Dr. Meyer if there is any evidence that alterations in the sedimentation rate (admittedly a nonspecific manifestation) are in any way related to change in concentration or the physical characteristics of the glycoproteins. I should like to ask Dr. Hawn how consistently the lesions which he described were produced in rabbits and whether there is any correlation between the rate of antibody formation and the appearance of these lesions. I also wish to call attention to the fact that the lesions produced by the injection of normal protein derivatives were acute lesions. While that may be analogous to those seen in rheumatic fever, they do not appear related to the chronic proliferating lesions which we see in rheumatoid arthritis.

Dr. John R. Paul (New Haven, Connecticut): How much are we dealing with non-specific changes, and to what extent do these changes, of which we have seen so many examples, have to do with rheumatic fever and rheumatoid arthritis?

Dr. Meyer spoke of substances inhibitory to hyaluronidase. We have been interested in our laboratory in some work by Friou and Wenner, ${ }^{1}$ indicating that in patients with rheumatic fever there was an increase, not striking but definite, of an " anti-hyaluronidase substance " in the blood stream, and there was a moderate increase in patients with haemolytic streptococcal infections. Does Dr. Meyer have any possible explanation for this finding in rheumatic fever?

DR. David H. King (Los Angeles, California): Does Dr. Meyer accept the conception of the dual nature of synovial effusions; one fraction being a dialysate from the blood, and the other produced by secretion of special cells in the synovial membrane?

DR. Russell L. CeCIL (New York): Is a collagen fibre a part of the connective-tissue cell? How does fibrinoid degeneration differ from old-fashioned hyalin degeneration? I get the impression that the fibrinoid degeneration, while an interesting phenomenon, is almost universally found in chronic inflammatory and degenerative tissue.

Dr. Walter Bauer (Boston, Massachusetts): Will Dr. Hawn tell us what type of lesion he observed when he employed small doses of albumin and globulin? Has Dr. Gross noted any appreciable difference in the collagen of the newborn as compared to that of the aged? Would Dr. Meyer tell us more about the synthesis and breakdown of hyaluronic acid, even at the expense of postulation? Can Dr. Klemperer explain the differences in cellular response which we observe in these diseases? For instance, the cellular response seen in serous cavities in lupus erythematosus may differ greatly from that seen in some of the allied diseases. Would he comment on the specificity of these collagen lesions? How does he observe them in other diseases? Has he seen cases that present the classical findings of lupus erythematosus disseminatus and yet at autopsy are found to have the characteristic lesion of periarteritis nodosa? If so, how does he interpret them?

1 J. infect. Dis., 1947, 80, 185.
Dr. Francisco P. Miranda (Mexico City): I should like to say a few words about the work of Dr. Guerra, in Mexico, on the question of the possible explanation of salicylate action of hyaluronidase. He has been using Evans's blue as a detector of the spreading factor, showing by measurement of the area of spreading of Evans's blue in the connective tissue the relative spreading factor in different patients, and he has found that rheumatic patients form one of the groups of those who have great spreading tendency in their connective tissue.

In Mexico we are convinced of the importance of connective-tissue lesions. Dr. Perrin and Dr. Evaro have been studying patients with rheumatic fever, and cadavers of patients dying from rheumatic fever, and have found a very constant lesion in the periosteum, so that these lesions can be proved to be of rheumatic fever origin. There have also been others working on this in Mexico. In this connexion I should like to ask Dr. Meyer and Dr. Hawn what is the relative quantity of lymphocytes and polymorphonuclear leucocytes they find in inflammatory reactions? This question is important, to my mind, because the question of the place of antigen formation is now believed to be within the lymphocytes rather than other cells. There are two steps in the question of the relation of antigen and antibody: first, the production within the cells of these antibodies; and, secondly, the liberation of these antibodies by the destruction of the lymphocytic cell, which is probably initiated by the action of corticotropic hormone. These relations can be found in the question of the velocity of the disappearance of lymphocytes from the site of the reaction.

\section{Closing Discussion of Symposium on Collagen}

Dr. Jerome Gross (Cambridge, Massachusetts): Dr. Freyberg asked whether or not we are studying abnormal connective tissue. We have felt the need of learning a great deal more about the normal before we felt competent to handle abnormal material. There is considerable variation in what can be observed in normal connective tissue depending on its source and the method of preparation for electron microscopy. Therefore a knowledge of the effect of various procedures is necessary before the identification of pathological changes is possible. The study of abnormal connective tissue is contemplated as soon as we feel sufficiently informed about the normal state.

Dr. Bauer wanted to know whether we had found any difference between the connective tissues of young and old. The first human material I had an opportunity to examine came from the skins of a seven-month-old premature and an eighty-nine-year-old gentleman. The baby's collagen was embedded in masses of gelatinous material which was not easily separated, which made it very difficult to obtain clean enough fibres. On the other hand the old man's collagen was very easy to clean and showed considerable fine structure. This important problem is also slated for future study.

Dr. KARL MeYer (New York): The first question was about erythrocyte sedimentation rate in rheumatic fever and rheumatoid arthritis and its relation to hyaluronic 
acid. A few years ago we published a paper in which it was shown that intravenously injected highly polymerized hyaluronate in guinea-pig and rabbit caused a marked increase in the erythrocyte sedimentation rate (ESR), which disappeared promptly after intravenous injection of hyaluronidase. It was further found, but not published in detail, that purified testicular extracts abolished in vitro the elevated ESR of rheumatic fever patients in 100 per cent., and of rheumatoid arthritis patients in 50 per cent. of the cases. However, this effect was later shown not to be due to the hyaluronidase contained in the testicular extracts, but to an enzymatic action on some component of the stroma, as Dr. Ragan has shown. What this component is we do not know. The ESR-increasing effect of hyaluronic acid is a property common to all high polymer linear colloids, regardless of their chemical nature. It might be suspected that in rheumatic diseases such linear colloids of connective tissue enter the blood stream.

Dr. Paul's question was whether we had any information on hyaluronidase inhibition in rheumatic fever and haemolytic streptococcus infections. The test for inhibitory action on hyaluronidase is complicated, since it depends on the purity of both the enzyme and the substrate and on the salts present. Under certain experimental conditions, for example, heparin has been shown to be a very powerful inhibitor of hyaluronidase. We have shown that hyaluronic acid samples, especially those from umbilical cord, may contain potent inhibitors of hyaluronidase; these inhibitors can be removed from the hyaluronate.

Group A haemolytic streptococci, however, do contain a very powerful inhibitor of hyaluronidase, which seems quite different in nature from the inhibitors found in serum and tissues. The study of the latter seems to me very much worth while.

As to the question of Dr. Kling, we believe in the dual nature of the origin of synovial fluid, namely, that part of the fluid is formed by dialysis, especially most of the water and diffusible elements; but that part of it, especially the hyaluronate, is formed by a secretory process requiring energy-producing reactions.

The question of Dr. Bauer about breakdown and synthesis of hyaluronic acid is one of the most fundamental problems for which we would like to know the answer. We do not know with certainty which cells produce hyaluronic acid. We suspect that fibroblasts do the synthesis. Then the question arises whether or not the same cells of the dermis or of the umbilical cord synthesize chondroitin sulphuric acid beside hyaluronic acid. We feel quite certain that hyaluronidase has no synthetic function, that is, synthesis and breakdown take completely different pathways as, for example, in glycogen. It seems at the present time that the synthesis is very complex. The synthesis of the basic disaccharide unit probably takes place in the liver. These circulating disaccharides may then be polymerized by mesodermal cells into the final polysacccharides.

The breakdown of hyaluronic acid is simpler but is also due to a number of enzymes which have not yet been separated. The difficulty here is the absence of well-defined substrates, which may have to be synthesized.
DR. C. v. Z. HAWN (Boston, Massachusetts): In answer to the first question, I know of no simple explanation of the observed difference in the rates of disappearance from the circulation of the injected albumin and gamma globulin. I think it would be naive to explain the difference only on the basis of molecular size, shape, or weight. The observed difference merely poses a problem rather than answers one.

We have not yet investigated antigens other than these supposedly normal proteins. We hope in the future to use proteins which have been chemically altered. These may provide more useful information than the native proteins alone.

There was a question raised as to the frequency and consistency of these observed lesions and the correlation with the rate of disappearance of antigen and the formation of antibodies. There was a correlation between the rapidity of evolution of the lesions and the rapidity with which the antigen disappeared from the circulation. There was also a correlation between the proportion of animals showing lesions and the proportion developing antibodies after the injection of a particular protein solution.

I am well aware of the fact that I have described only the evolution and repair of acute lesions. As Dr. Klemperer has emphasized, the tissues can react in only a few established patterns of sequences to a large number of different noxious stimuli. It would be fallacious to accept these experimentally produced lesions as the counterparts of clinical disease entities. However, there is experimental evidence from other investigators that chronic diseases, particularly nephritis, may result under the conditions of certain experiments dealing with in vivo union of antigen and antibody. The speculation seems justified that when antigens are used which are chemically far different from the experimental animal's own substances, the mechanism for the removal of these may be more complicated than that with simple heterologous proteins, and more complicated histological sequences may result.

In answer to Dr. Bauer, we have not systematically investigated the amount of antigen required for the production of these lesions. The described amount, $1 \mathrm{~g}$. per kilo of body weight, was first tried when we were investigating the possible use of crystallized bovine albumin as a blood substitute in treatment of shock during the war. Inasmuch as an experimentally reproducible disease in some of the rabbits was observed after such injections, we have arbitrarily adhered to the original amounts of protein for these preliminary investigations. I doubt whether such a large injection is necessary, since I have seen several isolated instances in other experiments where much smaller amounts of antigen elicited comparable lesions.

The character of the cell exudate is a problem of great interest. I think the earliest lesions we have seen have been infiltrated by lymphocytes and monocytes. The polymorphonuclear leucocytes appear in large numbers after the lesion is already established, and in the milder lesions they are often absent. We are at present investigating the possibility of preventing lesions by depression of the lymphocytic series by various means. 
Dr. Paul Klemperer (New York): Regarding the guestion on metachromasia and other muco-polysaccharides, it has been claimed that toluidine blue metachromasia is characteristic for sulphuric acid esters of high molecular weight. I am not quite able to support this statement because in the umbilical cord, which contains a great deal of polysaccharides, some metachromatic material is found that differs in its colour from that of typical metachromasia; this might well be hyaluronic acid. Unfortunately, there are not yet available reliable methods for mesenchymal mucus other than the one of toluidine blue metachromasia. There is a recent histochemical method for hyaluronic acid, but so far it has not given me satisfactory results.

I think today histologists are more or less agreed that the collagen fibre is no part of the cytoplasm of the fibroblast. I do not want to enter into the whole problem of fibre formation. I believe, in view of the original histologic investigations, the tissue culture experiments, and especially Wolbach and Howe's research in scurvy, that the collagen fibre develops from the homogeneous ground substance. Of course, the ground substance most likely derives from the fibroblasts, although the mechanism of its production still awaits further investigation. It would be interesting to repeat the experiments of Wolbach and Howe, to see whether the droplets within and outside the fibroblasts in scurvy are mucopolysaccharides.

Regarding the relation of hyaline to fibrinoid, hyaline is a purely descriptive term and does not denote more than a substance which is homogeneous and eosinophilic. According to this definition, fibrinoid would belong to the general group of connective-tissue hyaline. Differentiation of the hyaline substances is possible with the conventional methods of histology. Fibrinoid stains like fibrin, while other connective-tissue hyaline stains like collagen and has the $x$-ray diffraction pattern of collagen. I think I indicated in my remarks that the further analysis of the so-called fibrinoid alteration of the collagen fibre is of importance. I avoid speaking of fibrinoid "degeneration" because I do not know whether we should apply this term to alterations of an extracellular substance.

The cellular response in various diseases of the collagen tissue is a fundamental question. So far we can only say that there are definite differences in the cellular response. If one has the opportunity to examine early lesions in lupus erythematosus with fibrinoid alteration of the collagen tissue of the myocardium, one finds proliferation of fixed connective-tissue cells; but one never sees in lupus that conspicuous and characteristic differentiation into Aschoff cells seen in rheumatic fever. The cells evidently respond to the injury of the extracellular substances; they proliferate, but rapidly decay. One has to stress these subtle differences because they point to a possible fundamental difference in the pathogenesis of these two diseases. I think the question touches also upon the low white cell count in lupus erythematosus. However, I do not know the reason for the suppression of leucopoiesis, because this is a problem that is not answered by morphologic investigation of the bone marrow. It might be pointed out that if a patient with lupus erythematosus develops a secondary infection, such as cerebrospinal meningitis, the white cell count goes up.

Regarding the question of the specificity of collagen tissue lesions, I do not think that fibrinoid alteration should be considered specific. It is, however, of great importance because its presence is of diagnostic assistance in the individual case, and beyond that it has stimulated further inquiry. I think one must distinguish between two aspects of anatomic pathologic investigation. On the one hand it aims at establishing a diagnosis; this is interesting and important for the pathologist and helpful for the clinician. However, the ultimate object of anatomic pathology is to determine the fundamental nature of manifestations of disease as expressed in morphologic alterations.

Like other investigators, we also have found fibrinoid alterations in the affected vasculature in periarteritis nodosa; but in other sites, except for the valvular endocardium, it is not as common as in lupus erythematosus. In periarteritis nodosa and in rheumatic fever with striking vascular implication, glomerular lesions of the type seen in lupus erythematosus are not present. There is one alteration to which we paid little attention in our report in 1941, namely, the swelling of the connective-tissue ground substance. This, I believe, is a significant feature of the morbid picture and should be further investigated.

Typical periarteritic vascular lesions were found in only one of our cases of acute lupus erythematosus. This was an old case, records of which were kept in the files of our laboratory for some time before I came to the hospital. I cannot deny that the vascular changes were those of classical periarteritis nodosa.

\section{OTHER PAPERS}

\section{Rheumatic Patients in the Armed Forces}

\section{MAY G. WILSON, JOAN W. PAYSON, and ROSE LUBSCHEZ}

Two hundred and sixty-eight patients under medical supervision in the Children's Cardiac Clinic were of military age. Two-thirds volunteered or were drafted; one-third were rejected. The above authors presented the previous rheumatic history and degree of cardiac damage of 242 servicemen and rejectees. The distribution of the men in various services, military installations, and overseas theatres was given. A comparison of the morbidity among the men was presented for $\mathbf{4 0 0}$ patient years of experience in each group. The incidence of rheumatic fever was no greater than expected in civilian life. The reported high incidence of rheumatic fever in the World War 1939-45 was discussed. Data obtained from the Office of the Surgeon General, Selective Service Headquarters, and other sources, was analysed. Since data about the number of rheumatic susceptibles inducted were non-existent, it was assumed-on the basis of clinical experience- 
that about two-thirds of the rheumatic susceptibles who presented themselves were inducted. By applying the civilian recurrence rate of 4 per cent. to an estimated pool of rheumatic subjects in service, the number of recurrent attacks of rheumatic fever which should have been observed in the armed services was estimated. Except for the Navy data, there was close agreement between the number of rheumatic recurrences expected and the number of attacks of rheumatic fever reported. It was concluded that most of the reported attacks of rheumatic fever in the armed services were recurrent attacks, and that the risk for recurrent attacks of rheumatic fever was no greater in the services than in civilian pursuits.

\section{Discussion}

DR. R. L. WARE (Bureau of Medicine and Surgery, U.S. Navy, Washington, D.C.): Dr. Wilson's paper is interesting from the Navy viewpoint in that it highlights one of the major problems that we experienced during the war years. Rheumatic fever has to be considered among the top eight or ten conditions in importance to the Navy during the war. It ranked fourth among all diseases and non-combat injuries as a cause of sick days, and it ranked fifteenth as a cause of separation from the service by medical discharge.

The Medical Department of the Navy has recognized the importance of rheumatic fever in the service by setting up special treatment centres and by assigning research units to conduct studies of the disease. In the Division of Medical Statistics we are undertaking a statistical study of the 21,000 cases of rheumatic fever that occurred in the Navy during the war. We are interested in knowing whether local climate influenced the development of rheumatic fever. We are also interested in determining what effect, if any, the state from which a man came may have had upon his developing the disease. We will also examine the association of incidence rates for streptococcal disease, as exemplified by scarlet fever, with the rate for-rheumatic fever; and, in individual patients, the relationship of an attack of rheumatic fever to a preceding attack of scarlet fever. It is believed that the data under study may yield interesting information on these and other related aspects of the disease.

Dr. Elvira M. Deliee (New York): Dr. Wilson has had the enviable opportunity of following a large group of rheumatic children through adolescence into adult life and the armed forces. The great advantage which her patients have had, as I see it, is the opportunity for accurate diagnosis and uniform observation prior to military service. I am certain that a large proportion of recruits did not have the benefit of similar long-term supervision. Also, many who had rheumatic disease were totally unaware of its existence, physical signs in the heart either being absent or having regressed.

I should like to make a plea for the development of rheumatic fever registers in communities where appropriate diagnostic and supervisory facilities are available. The rheumatic fever problem is essentially a community responsibility because the disease is most prevalent in the low income groups. Furthermore, since the disease most commonly has its onset in children of school age, the rheumatic fever problem is, of necessity, closely integrated with the school health programme.

Recently, using the methods employed previously by Paul, I had the opportunity to conduct a school survey in the Lower East Side District of New York City. This survey was conducted with Dr. Charles Connor and Dr. Mortimer Weber, of New York University College of Medicine: 1,190 eighth grade children* were examined. Thirty-nine, or 3.3 per cent. of these children, were found to have existing or potential rheumatic heart disease. In addition, seven children were on home instruction or in special convalescent facilities, so that the incidence of rheumatic fever in these eighth grade children was nearer 4.0 per cent. It was found that thirteen, or onethird of these children were unknown to the School Health Service as having rheumatic disease. Five were totally unaware of the existence of their rheumatic disease. Conversely, four children had been wrongly - diagnosed as having rheumatic heart disease. This state of confusion is well known to others who have made school surveys for rheumatic disease. A rheumatic fever register with cumulative evidence on each rheumatic child, based on accurate and verified diagnoses, would contribute materially to the solution of this problem. The register, furthermore, would serve as the basis for an organized community effort for the study and control of rheumatic fever.

\section{Cardiac Changes in Rheumatoid Arthritis}

\section{WILLIAM S. CLARK and WALTER BAUER}

Cardiac abnormalities were studied in a group of f orty-five patients with definite rheumatoid arthritis on whom autopsies had been performed. The average age of the group at the time of death was fifty-one years and the average duration of the disease was twelve years. The diagnosis of rheumatoid arthritis was substantiated by typical clinical $x$-ray and histological findings. In all but two instances, no evidence of previous episodes of rheumatic fever could be demonstrated. In reviewing the clinical histories it was found that 50 per cent. of the patients had had evidence of heart disease before death. It was considered that hypertension and/or arteriosclerosis had been concerned in the aetiology in $\mathbf{5 0}$ per cent. of these, and rheumatic fever in 30 per cent. There were six instances of pericarditis. Seven patients had evidence of valvular disease. Mitral stenosis was demonstrable in five cases. At autopsy, atherosclerosis of the aorta and coronary arteries, usually with degenerative changes of the myocardium, was a rather constant finding. Focal myocarditis without definite histological evidence of rheumatic carditis was found in 16 per cent. of the

* The eighth grade corresponds to about the fourth form and is for children of about thirteen years of age.-Editor. 
total group. Pericarditis was found in $\mathbf{4 4}$ per cent. Twenty per cent. had some degree of valvulitis, which had resulted in mitral stenosis in fourteen of the total group. A definite diagnosis of rheumatic heart disease could be made in but one instance. A peculiar aortitis and aortic valvulitis with pannus formation was observed in one heart. In two hearts there were nodules indistinguishable from the subcutaneous nodules of rheumatoid arthritis. The cardiac findings in this group suggested the possibility that involvement of the heart might be a systemic manifestation of rheumatoid arthritis.

\section{Discussion}

DR. EDWARD F. Rosenberg (Chicago): Four years have elapsed since Dr. Baggenstoss and I reported the finding of a high incidence of rheumatic cardiac lesions in twenty-five individuals dying with rheumatoid arthritis. During this period developments regarding this observation have been most puzzling. Within a relatively short period reports from the University of Minnesota, from Montefiore Hospital in New York City, and from Yale University indicated that a high incidence of rheumatic cardiac lesions had likewise been discovered in series of autopsied cases of rheumatoid arthritis studied in those institutions. Dr. J. L. Hollander, of the University of Pennsylvania, told me recently that the series being studied under his direction is disclosing a similarly high incidence of rheumatic carditis.

This weighty evidence of the presence of inflammatory cardiac lesions in patients dying with rheumatoid arthritis is at variance with our observations regarding the condition of the heart in the living patient. Last year, with Drs. Weintraub, Bishop, and Hench, I reported that our earnest efforts to find rheumatic heart disease in a series of 150 cases had shown this incidence to be approximately 3 per cent.-about the same incidence as in a control series. Today we have heard Drs. Clark and Bauer report that the incidence of rheumatic heart disease was not high in their autopsied series.

All this indicates that the problem needs much more study. I have noted a recent tendency on the part of some cardiologists to teach that patients with rheumatoid arthritis often develop serious rheumatic heart disease. This may be the case, but we are not yet certain.

\section{Family Incidence of Rheumatoid Spondylitis}

\section{BERNARD ROGOFF and R. H. FREYBERG}

The families of 114 patients with rheumatoid spondylitis were carefully investigated to determine the family incidence of this disease. By careful history thirty-one patients revealed that other members of their family suffered with back disability. Eighteen of these families were personally examined, and ten ( 9 per cent.) were found to contain multiple cases of spondylitis. In one family three brothers and the father were found to suffer with spondylitis; in another, identical twins age 20 revealed bilateral sacro-iliac arthritis. In the thirteen unexamined families another 4 per cent. could be anticipated to reveal further involvement. Thus it is concluded that the family incidence of rheumatoid spondylitis lies between 9 and 13 per cent.

It was noted that among the relatives of spondylitics the incidence of extremity joint rheumatoid arthritis was less than 2 per cent. This was in marked contrast to the 9 to 13 per cent. incidence of spondylitis. It is suspected that the factors influencing the family incidence of rheumatoid disease are more closely related to comparable tissues in relatives than to connective tissue in general.

It is the responsibility of the managing physician to attempt to discover other cases of spondylitis among families of spondylitics.

\section{Discussion}

DR. Robert H. TALKov (Boston, Massachusetts): A family survey of 293 cases of rheumatoid arthritis is being made (but is not yet completed) at the Massachusetts General Hospital for periods of ten to seventeen years, as compared with a control group of equivalent number and average figures of four series reported in the literature. The incidence of rheumatoid arthritis in one or more members of the family was $11.9,5 \cdot 3$, and 20.6 per cent. respectively.

In a more detailed study 50 patients, selected in the order of their appearance at the clinic, were carefully questioned. Follow-up information was obtained by contacting or examining various members of the family, corresponding with their physicians, and searching hospital records. It was of interest to find that 32 per cent. gave a positive family history of rheumatoid arthritis, and in an additional 4 per cent. the occurrence of the disease was considered possible.

The records of 230 patients with rheumatoid spondylitis segregated into Group A (including shoulder and hip involvement) and Group B (including peripheral joint involvement) were studied. The familial incidence of rheumatoid spondylitis was 5.9 per cent. in Group A and 2.7 per cent. in Group B, whereas generalized rheumatoid arthritis was present in $\mathbf{1 . 2}$ per cent. of Group $A$ and 8.9 per cent. of Group B. These figures appear to bear out those presented today, namely, that the incidence of spondylitis is greater in the families of those having spondylitis.

Dr. Howard F. Polley (Rochester, Minnesota): Drs. Rogoff and Freyberg are to be complimented on the detailed manner in which this study was approached. One of the main difficulties in analysing a study such as this is brought out by their emphasis of the careful questioning that is necessary to elicit a complete and reliable family history. In our study of 1,035 cases of rheumatoid spondylitis reported last year at this meeting and to which Dr. Rogoff referred, several interesting features of the family history of patients with rheumatoid 
spondylitis were noted. We examined two sets of identical male twins. In each instance one twin had rheumatoid spondylitis while in the other evidence of rheumatoid spondylitis or arthritis had not developed. The most extensive family history encountered was that obtained from a woman thirty-five years of age who had rheumatoid spondylitis. One of her brothers had died at the age of 42 after having had both rheumatoid spondylitis and peripheral rheumatoid arthritis for twenty years; another brother, aged 50 years, had had rheumatoid spondylitis and rheumatoid arthritis for eighteen years and a third brother, aged 38 years, had had rheumatoid spondylitis for seven years. The patient had three sisters who apparently did not have the disease.

In our series of 1,035 cases the recorded incidence of a family history of rheumatoid spondylitis was 0.4 per cent. the incidence of a family history of peripheral rheumatoid arthritis was essentially the same. The family history was not complete in all the cases in our series. We are, therefore, hesitant to emphasize these particular data without further study.

The finding of a family history of rheumatoid spondylitis or rheumatoid arthritis in cases of rheumatoid spondylitis is interesting, but other factors unknown at the present time may become more significant as understanding of the aetiology of rheumatoid spondylitis is advanced.

DR. R. M. Stecher (Cleveland, Ohio): These findings come as a great surprise to me because we investigated this subject and failed to find many references in the literature to the familial incidence of spondylitis. The disease does occur as multiple cases in the same family. Now that we have established the fact that it is a familial disease, the next step is to investigate the manner in which it is inherited, its genetic characteristics. For that, it is important that we know not only the number of people involved but also the number of people who are not involved, and it is also important to know how many members of the family there were, and I would suggest and hope that in all these studies, when they are finally published, they include not only the number of brothers but also the number of sisters.

Since our paper was published, we have been surprised at the additional cases that have come to our attention. We have had two sets of sisters. I have a letter from a man in Canada who had a set of brothers, and Dr. Kuhns has also given us a report of his figures.

Dr. Edward F. Rosenberg (Chicago, Illinois): I am sure this observation is sound and I have already put it to practical use. I am so convinced that the incidence of rheumatoid spondylitis is high among brothers of patients with this disease that $I$ now urge radiographic examinations for all male siblings of spondylitis patients. By this means I discovered five cases in the past year.

DR. B. Rogoff (closing): I am glad Dr. Rosenberg made that last comment. It is the responsibility of any doctor examining a case of rheumatoid spondylitis to question very carefully about relatives with any back disability, and it is his responsibility to examine those patients and institute proper treatment. Thus we may hope for better results.

\section{Heberden's Nodes : Relationship of the Menopause to Degenerative Joint Disease of Fingers}

\author{
ROBERT M. STECHER and \\ EDMUND E. BEARD
}

The time relationship of the development of Herberden's nodes to the menopause was observed in a hundred women. The exact onset of either event could not be sharply identified in most cases but, in general, it was found that Heberden's nodes occurred earlier in women with early menopause than in women with late menopause. The range of age of menopause was 28 to 56 years, the average age 48.55 years, the median age 49.3 years, and the standard deviation $\pm 5 \cdot 2$ years. These figures were similar to those found for a control group of 96 women. The age of onset of Heberden's nodes ranged from 33 to 65 years. The mean age was 48.8 years, the median age 48.8 years and the standard deviation \pm 6.8 years. The coefficient of correlation for these two events in each individual was \pm 0.459 , \pm 0.079 , which is significant. These authors also discussed the possible influence of the known physiological changes of the menopause upon Heberden's nodes and other bone and joint disease, and the relationship of the menopause to other joint disease, to menopausal arthritis, and to menopausal arthralgia.

\section{Discussion}

Dr. Phulip S. Hench (Rochester, Minnesota): Although Heberden's nodes are the most obvious expression of osteo-arthritis, little is known about them. Dr. Stecher and Dr. Beard suggest that the menopause may be casually related to the development of Heberden's nodes but they are not suggesting that Heberden's nodes constitute a form of " menopausal arthritis". This distinction is important. Dr. Stecher and Dr. Beard derived little value from their review of the literature, which supports, with about equal fervour, four ideas: namely, that the menopause is definitely related to Heberden's nodes, that it is not, that it may be, or that nobody knows whether or not it is. In other words, previous workers have scarcely got beyond the realm of clinical supposition or speculation or the most elementary statistics. In support of the proposition of a relation between Heberden's nodes and the menopause, previous workers have offered no pathologic evidence indicating that the pathologic reactions in Heberden's nodes are of a distinctive type characteristic of "menopausal arthritis", nor any impressive clinical evidence from the results of substitution or endocrine therapy.

Premature Heberden's nodes in women aged 30 to 35 years have been seen not uncommonly by Dr. Slocumb and myself. A sufficient number of these patients have also developed premature grey hairs or premature menopause or both to suggest to us the idea under discussion 
and to make it seem attractive. However, these examples are rather striking exceptions, and in general we have been unable to link the menopause with the pathogenesis of Heberden's nodes.

I would draw the following six tentative conclusions: (1) The menopause is obviously not the primary aetiologic factor in Heberden's nodes. (2) The menopause may or may not be a secondary (conditioning or aggravating) factor in their development. (3) Despite statistics, the relationship between menopause and nodes may be largely coincidental, one no more definite than that between the menopause and the orderly development of grey hairs or mild arteriosclerosis or hypertension. (4) If the relationship between menopause and nodes is not purely coincidental it may be that the menopause is not the "parent" of the nodes but their " sibling" and that some other factor is the common cause of both menopause and nodes. (5) Since Heberden's nodes may develop among men, no unisexual hormone can be involved. If any hormone is concerned it must be bisexual, and one could hardly expect Heberden's nodes to respond to the use of female hormones. (6) When it is recalled that trophic disturbances of an extremity, such as those which occur with poliomyelitis in childhood, prevent forty years later the appearance of Heberden's nodes in the neurologically affected side, it is difficult to believe that a deficiency or an excess of any hormone can be the major cause of these nodes.

Until more hormone assays and other biochemical studies have been made in many cases of Heberden's nodes we cannot conclude that the menopause certainly constitutes an aetiologic factor of prime importance in the development of the osteo-arthritis of Heberden's nodes.

Dr. Russell L. Cecil (New York): At the time Dr. Archer and I published our study on menopausal arthritis, the criticism was made that these two conditions were purely coincidental and that what we were talking about was merely osteo-arthritis occurring in middleaged women at the time of menopause. That was a fair criticism, but the fact remains that women who have artificial menopause, particularly in the twenties and early thirties, will often have severe arthralgia along with the other well-known signs of menopause. One would expect that if there were some connexion these pains would be relieved by oestrogen therapy. In my experience, however, the use of oestrogens in the treatment of these menopausal arthralgias has been disappointing.

\section{Vitamin D Toxicity Simulating Hyperpara- thyroidism}

\section{CHARLES H. SLOCUMB}

Vitamin D poisoning produced symptoms and also radiographic' and laboratory findings similar to those of hyperparathyroidism, with or without changes in the bones, metastatic deposits of calcium, and renal damage which may or may not be rever- sible. The most common early symptoms of vitamin D toxicity were polyuria, polydipsia, nausea, vomiting, occipital headache, or pruritus. The early laboratory findings were elevated concentrations of serum calcium and blood urea and increased urinary excretion of calcium. Severe vitamin $D$ poisoning produced deposits of calcium in nodules, tophi, and arteries, osteoporosis with destructive and cystic areas in bones, uraemia, and anaemia. Dosages of vitamin $\mathrm{D}$ as low as $\mathbf{5 0 , 0 0 0}$ units daily may produce severe toxic reactions. For no widely used preparation of vitamin $D$ can the claim be made that it will not produce such toxic reactions. Recognition of vitamin D poisoning should temper such enthusiasm as remains for the therapeutic use of massive doses of this vitamin.

\section{Discussion}

Dr. David H. KuIng (Los Angeles, California): In the arthritis clinic of the White Memorial Hospital and in private practice our experience was the same as Dr. Slocumb's.

(Several slides were demonstrated showing enormous metastatic calcification around the joints, which occurred in a 37-year-old patient with rheumatoid arthritis who took 150,000 to 250,000 units of vitamin $D$ daily for about two years; a high alkaline ash diet with two quarts of milk daily was a contributing factor. By withdrawal of the vitamin $\mathbf{D}$ and change of diet, most of the metastatic calcifications disappeared in four months; the blood calcium dropped from 14 to $10 \mathrm{mg}$. per $100 \mathrm{c.cm}$. of blood. However, the shaft of the proximal phalanx of the fifth right toe showed a pathological fracture after the absorption of the calcification. The radiographs showed also arteriosclerosis of the popliteal artery, calcification in the kidney, and gallstones persisting after one year. The NPN remained high, over $60 \mathrm{mg}$. per cent., PSP excretion 25 per cent. Kidney damage therefore was irreversible.)

In a comparative study, 150 patients were treated with various brands of vitamin $D$ for two to nine months; a dose of 100,000 to 250,000 units daily was given. Toxic reactions occurred in about the same percentage with the various brands, the therapeutic results being equally poor.

Dr. Richard T. SMith (Philadelphia): It is deplorable that there have been bushels of vitamin $D$ passed out to patients all over the world, and so few cases of toxicity reported. We have had two cases of toxicity in Philadelphia, one in a 17-year-old boy with severe tophaceous gout, with a duration of three years, according to the history; because of the tophaceous gout in proximal interphalangeal joints, the diagnosis of rheumatoid arthritis was made. He was given vitamin D until he developed gastro-intestinal symptoms when it was temporarily stopped. The patient developed uraemia and died about two months after the vitamin $D$ was again instituted. He had sheets of calcium in the soft tissues and in the tophi, which drained large amounts of calcium along with the urates. One of the draining tophi finally 
spontaneously amputated through the terminal joint of a finger. There was no autopsy.

In another instance, a patient with spondylitis was given vitamin $\mathbf{D}$ and in a period of four months he showed symptoms of having renal calculi. Radiographs taken before the giving of the vitamin D showed no evidence of stones. When the symptoms began, there was radiographic evidence of stones and gravel in both kidneys.

Recently it has been called to my attention that a local physician going to a conference of supposed specialists in arthritis was told he should give vitamin $D$, one capsule a day, increasing even to nine a day, for arthritis. Vita$\min \mathrm{D}$ in concentrated forms is no longer a part of the programme of treatment at Jefferson. We have found evidence of calcium in the urine in patients who have taken only 50,000 units daily for seven days.

Nothing can be done to stop the practice of giving vitamin D as a prescription. The Pure Food Department would like it stopped but they cannot interfere as long as these preparations are sold on prescription. It must be up to us to stop the use of these dangerous drugs.

Dr. PhILIP S. Hench (Rochester, Minnesota): Vitamin D toxicity can be serious. As Dr. Slocumb has demonstrated, it can simulate hyperparathyroidsm or can produce other clinical pictures, with the development of mental confusion or even (non-uraemic) coma, or chronic nephritis with transient uraemia or with persistent progressive fatal uraemia. Much of the commercial advertising of concentrated vitamin D preparations for arthritis has been blatant, false, and objectionable, revealing half-truths and concealing or failing to mention the chances of significant toxicity. However, the advertising has been so effective that nowadays concentrated vitamin $D$ is being given, not only for rheumatoid arthritis, but a for variety of arthritides such as osteoarthritis or gout, or even for " aches and pains". Thus one must be on the alert to recognize vitamin D intoxication in anyone with " rheumatism", not only in those with rheumatoid arthritis.

Our metabolic experts at the Mayo Clinic have become aware of the current dangers of making a diagnosis of hyperparathyroidism (on previously acceptable grounds) in a rheumatoid or "rheumatic" patient, and in all such cases they now question the patients carefully relative to the use of any preparation of vitamins. However, often the patient is unaware that he has taken concentrated vitamin D. Some time ago I saw a patient with "muscular rheumatism" who was scheduled for parathyroidectomy the next day because, though she was sure she had taken nothing but two varieties of salicylates, she presented biochemical features of hyperparathyroidism and had diffuse musculoskeletal pains. We telegraphed to her physician and learned that when the first medication (salicylates) had given inadequate relief he had substituted concentrated vitamin $D$, which the patient thought was just another salicylate. The case turned out to be one of vitamin D toxicity involving a myofibrositic patient.

Even more instructive and disturbing was the following casse. An arthritic patient presented enough features of "coincidental hyperparathyroidism" to be listed for parathyroidectomy. At operation the surgeon could not find any tumour. Somewhat embarrassed, he turned to the gallery and assured them that he and the clinicians, having been quite aware of the possibility of vitamin D toxicity in an arthritic patient, had been informed emphatically by both the patient and the attending home physician that no vitamins had been given. At this juncture a voice from the gallery meekly said, "I wonder if the medicine I've been giving the patient is responsible." To this the suprised surgeon replied, "But what do you know about this case? Are you her home physician?" "No," answered the visiting physician, "I'm a relative and have been giving her vitamin D on the side." Thus it appears that sometimes not even the responsible attending physician knows that vitamin $\mathrm{D}$ preparations are being taken - truly a dangerous situation.

Because nephritis is so rare in cases of rheumatoid arthritis, I have used a maxim which was valid for many years: In a case of acute, recurring or chronic arthritis with nephritis or renal stones, suspect gout. However, rheumatologists are now encountering two varieties of of "pharmaceutic nephritis", that from gold and that from concentrated vitamin D. Hence we must modify the maxim and restate it thus: In a case of acute recurrent arthritis with nephritis or stones (radiographically non-opaque), think of gout, but in a case of chronic arthritis or even of vague "rheumatism" with nephritis or stones (radiographically visible) think of rheumatoid arthritis with pharmaceutic nephritis, chiefly vitamin D intoxication, and less commonly "gold nephritis".

Dr. Walter Bauer (Boston, Massachusetts): I am not surprised to learn of Dr. Slocumb's observations. On the basis of our own experience, I feel certain that such toxic reactions occur much more frequently than the medical literature indicates. In fact, intoxication may result from much smaller doses of vitamin $D$ than those usually employed in the treatment of rheumatoid arthritis. We have observed a hypercalcaemia varying from 11.2 to $14.2 \mathrm{mg}$. per $100 \mathrm{c} . \mathrm{cm}$. of blood for a period of twenty-five weeks, during which time the daily dose of vitamin D never exceeded 60,000 U.S.P. units.

Dr. Slocumb's report calls to our attention many interesting features of vitamin $D$ poisoning. As he points out, the renal lesions may be severe and longstanding. It is important to remember that in some instances they have been irreversible. In view of this latter fact, one might postulate that some of his cases may have developed secondary hyperparathyroidism of the type occasionally seen in association with chronic nephritis. Review of his data with this point in mind may throw additional light on the nature of the biochemical changes he has observed.

Dr. Charles H. Slocumb (closing): Renal stones were not mentioned because only two of the patients had renal stones. My associates and I were unable to demonstrate that these patients had not had the stones before they took vitamin D. However, the stones may have been related to the vitamin $\mathbf{D}$ poisoning.

I did not mean to imply that vitamin $\mathrm{D}$ poisoning 
produced arteriosclerosis, but it does cause deposits of calcium in the media of arteries. This has been well established in the pathologic studies of persons who have died of vitamin $\mathrm{D}$ poisoning. The deposits of calcium in the arteries may be distributed so finely that they may not show in radiographs.

I cannot answer the question regarding secondary hyperparathyroidism other than to point out that in the cases of renal damage that we have followed for two and a half to three years the concentration of calcium in the serum returned to normal, and that of phosphorus remained slightly elevated or returned to normal even though the concentration of urea did not go below 64 to $92 \mathrm{mg}$. per $100 \mathrm{c.cm}$. of blood. In spite of the renal damage these patients regained good health.

\section{Rheumatoid Arthritis in Patients Receiving Simple Medical and Orthopaedic Measures}

\section{CHARLES L. SHORT and WALTER BAUER}

This report is based on a follow-up study of 250 unselected patients with rheumatoid arthritis admitted to the medical wards of the Massachusetts General Hospital between 1930 and 1936. No patient was included who had received gold or vitamin $\mathrm{D}$ in massive dosage, whose follow-up was inadequate, or in whom the diagnosis was in question. The patients were rarely kept in the hospital more than a few weeks for diagnosis and accumulation of data and to receive instruction in general measures which could be carried on at home. Fifty-six patients died in the course of the study, with the results in such cases expressed according to the latest examination before death.

The average duration of follow-up was 9.6 years, with 80 per cent. under observation for more than five years. The latest examination of these patients gives the following results: improved, 53 per cent.; stationary, 13 per cent.; and worse, 34 per cent. Of the improved group, thirty-eight, or 15 per cent. of the series, were in remission. The most striking factor affecting prognosis was found to be the duration of the disease. Nearly three-quarters of those with duration of one year or less showed some degree of improvement, with an even higher percentage in patients seen in the first six months. In addition, males without spondylitis, patients under 40 , those with asymmetrical joint involvement, 'and those with mild involvement, activity, and total severity were likely to have a more favourable outcome. Factors of no importance in determining the patients' course included involvement of the spine, a history of prodromal symptoms, an intermittent course before admission, and an acute contrasted with a gradual onset. Others were a severe degree of anaemia, a family history of rheumatoid arthritis or rheumatic fever and, in women, onset within two years of the menopause.

The net relapse figures (35 per cent.) are comparable to those tabulated from a combined series of 768 patients improving under gold therapy. Twenty-three patients, or 9.2 per cent., could be considered " five-year cures".

In summary, certain clinical factors of prognostic value in rheumatoid arthritis have been outlined. But we have chiefly attempted to present a control series which may be used for comparison with groups of patients receiving special forms of therapy.

\section{Discussion}

Dr. Otto Steinbrocker (New York):-I admire the courage and persistence of the authors in carrying such a large group of patients for so long a period on ordinary measures. It must have been difficult to follow this course in spite of the many therapeutic enthusiasms of the past ten years, which must have been tempting.

There is no control group of patients in the literature, to my knowledge, carried for a long period without treatment, permitting us to study the uninfluenced evolution of the disease. This series approaches closest to that. This paper therefore constitutes, in my opinion, one of the fundamental contributions to therapeutic investigation of rheumatoid arthritis. It gives some of the essential facts of life in rheumatoid disease, by means of an extensive follow-up of the response to general measures and/or the lapse of time. Such basic information had been sorely needed in our understanding of the disease.

The control studies available are all too few and they usually lack lengthy follow-up. This paper provides for comparison two types of information to be distinguished in any special therapy. Initial response to treatment after an arbitrary period or course; and long-range results, which are much more important. It gives a therapeutic base line, at least for significant response, above which results of any palliative or specific must rise appreciably under the same conditions. It should prove a real asset for comparison of results for those clinics or individuals whose material is too limited to permit a control series of their own.

The response of different stages of rheumatoid arthritis may be a factor in the results. It would be helpful if, in the final report, such a classification is included together with the response of each stage.

Dr. Richard H. Freyberg (New York): This paper should become a basis for evaluation of special measures of therapy. However, there are certain factors not mentioned by the authors which should be taken into consideration. One is the speed with which improvement may occur, to bring about remission in the disease. This is important to the patient; any special measure of treatment which will lessen disability, leaving more hours and days of comfort and ability to work, has very significant value. This should be taken into consideration. 
A second factor is that of control by comparing different periods in the course of illness in the same patient, one period when no special therapy is used and another when a certain special measure is employed. This form of control becomes exceedingly difficult for, as Dr. Short has pointed out, what happens during one year in the course of this illness may in nowise be an index as to what may happen in another year in the same patient. Many times, however, this form of control is of distinct value, and it has not been used in this analysis.

Dr. Charles L. Short (closing): We had in mind the creation of a series something like this from the beginning, and we purposely refrained from giving the patients, or at least very many of them, so-called specific treatment. These were patients who came into the hospital, it is true, and possibly other series could be set up with patients of milder severity who came to a clinic. On the other hand, they do represent a cross-section, because certainly the minority of them were classified as severe.

We are not claiming that this form of treatment-that is, simple, general measures-necessarily has an effect on the course of the disease. I think that it is an open question, and Father Time must be given his due share of the credit.

As to the point Dr. Freyberg made about speed of improvement, I will say briefly that of the patients that showed ultimate improvement, in about two-thirds of them that improvement was manifest in two years, and in nearly four-fifths, within four years. We can also see from this series that a remission is possible and may occur even after the patient has been under observation a number of years.

\section{La Session annuelle de l'American Rheumatism Association}

Un symposium sur le collagène s'est tenu à New Jersey, le 7 juin 1947. La structure microscopique du _. collagène a fait l'objet de recherches au Massachusetts
Institute of Technology pendant les cinq dernières années; et le Dr. J. Gross a déclaré qu'il pensait que la découverte de la structure du collagène et des substances voisines pouvait fournir une base pour une meilleure compréhension de quelques troubles pathologiques qui se produisent dans les tissus conjonctifs. Le Dr. K. Meyer déclara que, histologiquement, il existe deux types se substances interfibrillaires: la substance fondamentale amorphe et visqueuse; et les céments métachromatiques proprements dits. Tous deux sont constitués principalement par des protéines et des polysaccharides. On peut faire entrer en corrélation la chimie des tissus conjonctifs et leur histologie en admettant que le substance fondamentale amorphe contient de l'acide hyaluronique tandis que les céments contiennent différents sulfates de chondroïtine comme constituants principaux.

Le Dr. C. V. Z. Hawn cita des expériences faites sur des lapins dans le but d'établir la corrélation entre la série des modifications pathologiques et immunologiques, et de comparer les réponses aux deux fractions chimiquement et immunologiquement distinctes des protéines plasmatiques et au sérum entier de la même espece. Le Dr. P. Klemperer conclut qu'il est nécessaire d'acquérir des connaissances plus fondamentales sur la nature et la cause de l'altération fibrinoïde des fibres de collagène avant de pouvoir attaquer le problème de l'étiologie de la maladie humaine caractérisée par les modifications du collagène diffus.

D'autres communications portaient sur les rhumatisants dans les forces armées (May G. Wilson et ses collaborateurs), les modifications cardiaques dans l'arthrite rhumatismale (W. S. Clark et W. Bauer), le caractère familial de la spondylite ankylosante (B. Rogoff et R. H. Freyberg), les nodules d'Heberden, et les rapports entre la ménopause et la maladie dégénérative des articulations des doigts (R. M. Stecher et E. E. Beard), la toxicité de la vitamine D simulant l'hyperparathyroïdie (C. H. Slocumb), et l'arthrite rhumatismale chez les malades recevant de simples traitements médicaux et orthopédiques (C. L. Short et W. Bauer). 